\title{
Historical epistemology foundation of social network across generations for building knowledge
}

\begin{abstract}
Historical epistemology is a new area of study which remains between at least three disciplines: sociology of science, epistemology and philosophy of science. History of science also remains in the background to provide material for supporting and illustrating the ideas and doctrines developed in this new research field. Because of its wider spectrum of subjects, many issues are discussed in relation to this new field. However, some of these issues have no relevance for the main purpose of this subject. For instance some "investigate the historically variable conditions under which fields of knowledge are formed." I would like to argue that historical epistemology must be concerned with the epistemological conditions under which historically and socially variable conditions are unified in the fields of knowledge. If we take historical epistemology in this sense as a new area of study that constitutes a new discipline then we need to define its subject matter and main problems that need to be discussed. As an attempt I would like to offer my opinion as to how we need to define this discipline which require an approach from sociological, epistemological and historical perspectives.
\end{abstract}

Keywords: historical epistemology, social network, scientific tradition, rheinberger, sociology of science, scientific revolution
Volume 2 Issue 3 - 2018

\author{
Alparslan Acikgenc \\ Department of Philosophy, Uskudar University, Turkey
}

Correspondence: Alparslan Acikgenc, Faculty of Human and Social Sciences Department of Philosophy Altunizade Uskudar, Istanbul,Turkey,Tel +9053279378I6, Email acikgenc@gmail.com

Received: April 0I, 20I8 | Published: June 04, 2018

\section{Introduction}

Sociologists and also philosophers of science recently focused on a problem concerning the foundation which makes possible transmission of knowledge from one generation of scholars to the next. In another sense, they are interested in finding how scientific development takes place. In this regard, "Gaston Bachelard argued that scientific development is driven by "recurrence", that is, by the polemical negation of past knowledge. [But] Ludwik Fleck emphasized that the sciences are "development conditioned"; that is, they are determined by the steps they have already taken. "Thought styles" structure these steps." These discussions concentrate on the sociology of scientific knowledge. Their aim is to reveal a social network across generations. ${ }^{2}$ This social network makes the transmission of knowledge across generations possible. What is missing in these discussions is the epistemology on the basis of which such a social network can be established. Rheinberger ${ }^{3}$ attempted to fill in the gap from this perspective but he was not quite successful as Kinzel also levels her critique:

My first criticism concerns the choice of examples. Rheinberger is not clear about his criteria for selection. It is not apparent why relevant traditions-such as the "Sociology of Scientific Knowledge" or the debates over "History and Philosophy of Science"-are missing in the book. ${ }^{4}$ Rheinberger is not interested in the social network in his essay; as he remarks, he is rather interested in "reflecting on the historical conditions under which, and the means with which, things are made into objects of knowledge. It focuses thus on the process of generating scientific knowledge and the ways in which it is initiated and maintained". It is clear that Rheinberger is not using the term "epistemology" in the traditional sense. This requires us also to explain what we mean by this term as we use it in our major concept "historical epistemology". Briefly we may explain this term on the basis of its traditional usage as the philosophical discipline which deals with the human knowledge system, which consists of our external and internal senses together with mental faculties such as memory, consciousness, imagination, intellect and intuition. In the classical approach the nature of these faculties were studied in psychology; but their operations were dealt with in epistemology. Presently we propose to study both in epistemology leaving the physical operations to biology rather than to psychology. Hence, epistemology as we take here is the discipline of human knowledge system; in other words, it is the science which discusses the nature of knowledge system within human body and its operations during a knowledge activity. As defined here this is pure epistemology.

The historical study of philosophical epistemology would be the historical study of efforts to gain philosophical understanding or knowledge of the nature and scope of human knowledge. On the other hand, we need to investigate the foundation of knowledge traditions as processes in history so that we can observe the social network governing this process. Moreover, we need to understand sociological concept of 'tradition' so that we can defend this concept. I would like to unfold the mental states that support our knowledge activities as human behavior; this is indeed an applied epistemology to our scientific activities. For, there are certain mental states that act as epistemological frameworks for our scientific behavior. These frameworks render knowledge a product of a process in history and since this process is continuous within a social context an activity that is purely epistemological is colored with social traits of this context. 
It is this very phenomenon that I perceive as "historical epistemology" which is different from Rheinberger's approach. As a preliminary study, I shall take historical epistemology as "epistemology proper applied to the history of knowledge activities" (which includes scientific activities as well) in a society or a civilization".6 I would like to argue that historical epistemology can explain how a new 'tradition' but more properly a scientific tradition as well as knowledge tradition arises within a civilization. But this tradition and the historical process leading to this tradition is governed by "human epistemology" which can be entitled "human knowledge system" as imbedded in human nature. Therefore, a brief analysis of human nature is in order as this will help us understand the way traditions come to emerge in a society. This analysis will be again from an epistemological perspective not sociological. Moreover, we find this perspective to be critical for the emergence of scientific traditions also. This phenomenon would be relevant for our discussion of historical epistemology.

\section{The concept of tradition}

Humans manifest four levels of existence as their nature; animality, emotionality, rationality and spirituality.7 At all these levels tradition is perceived and manifested differently. At the animal level there are only habits of behavior which can hardly be defined as tradition. We see the true marks of tradition beginning at the emotive level. But at the rational level it is turned into a doctrinal understanding which is found in civilizations. We may define tradition in terms of custom as "a specific custom or a collection of customs elaborated to a doctrinal level". A custom is understood as a habitual behavior assigned by togetherness. This means that there are four basic characteristics in every tradition: the togetherness, or rather the social context; regularity of behavior as a repeated sequence; continuity in history; and finally doctrinal understanding. With respect to the first characteristic we can say that there cannot be tradition without the society. There is participation in tradition by the members of the community and there is also the community that provides an environment for tradition. When certain behavior is repeated over a period of time in such an environment it becomes a habit of a certain individual. But since this habitual behavior is carried out within a social togetherness others may participate in this behavior. If it is recognized by an overwhelming majority of the communal togetherness it becomes a custom. Usually a custom has historical continuity, but this is not necessary for it. A custom may arise and disappear within a span of time in a social context. But traditions are continuous in history, at least for a long period of time. That is why they preserve a collective memory of the culture and in order to make the continuity possible the society, parallel to this preservation, develops a whole conceptual scheme to interpret and re-interpret the tradition providing it thus a cognitive content as well. It is for this reason that we claim an epistemological basis for traditions. This amounts to saying that a tradition is based on human nature including the knowledge system with all its aspects including the system of knowledge found in human animality, emotionality, rationality as well as spirituality. 8

We may differentiate between two traditions: The first is the social tradition in general and the second is the scientific tradition in particular. If we explain the first one then the second one would be quite similar to it and then we need to deduce only the differences between them. This is because social tradition is emerged within a society; so is a scientific tradition. Bu the former is based on a larger social environment in which all the living individual are involved; whereas a scientific tradition is based on a community where only scholars are involved. Let us consider the first again in order to further clarify what we have said. A tradition emerges after a long process within a social context. It arises as a result of our social and epistemological nature. If we analyze the way tradition emerges in a social context out of the systems embedded within human nature this point will be clear. We know that in philosophy human being is defined as "rational animal". This definition ascribes two essential characteristics to human nature: animality and rationality. We argue that this definition does not capture the human nature completely because rationality does not express his/her other aspects that belong also properly to his/her essential nature and in fact as an essential differentiating factor from the other species under the same genus. We may argue in this respect that a human being is emotional in such a way that no other animal is emotional. Furthermore, a human being is social in such a way that no other animal is social. Are we then to include emotionality and being social in our definition? If we can show that these aspects of human being do represent a complete nature in him then we must include in our definition. Let us then express the character of being a social as togetherness. In this case we may confidently assert that emotionality and togetherness also belong to human nature as essential elements. We need to re-analyze the human nature in order to wrest our understanding of human nature from the dominating historical conception. We shall defend this definition as a basis for our sociology of tradition: "Human being is an emotional, social (togetherness) and rational animal."

Let us pose and think: Is tradition in a society produced only as a result of social dealings? If we count some other factors besides social dealings among the formation of traditions such as physical environment, human psychology and perhaps more factors among other aspects of human nature, then we are equally justified to accept our system of knowledge and indeed as a major one among the factors leading to the formation of tradition in a society. From this we may conclude that any social phenomenon that builds gradually through a historical development and is perceived by our rational faculty must carry marks of human knowledge system which is investigated by pure epistemology. If this conclusion is accepted then we must also accept the fact that there must be an applied discipline as a branch of pure epistemology that investigates how human knowledge system functions through history that generate a phenomenon which is knowledge in this case.

\section{The concept of scientific tradition}

A scientific tradition then is similar to the social tradition in general which we have briefly identified. In other words, they both are of the same species of social phenomenon. However, the difference is that a scientific tradition has two societies, the first is the social context and the second is the scientific community which gives an epistemological character to its tradition. But this difference is significant because such a community has a certain purpose which characterizes its tradition. We may cite the following as the characteristics of any scientific tradition warning that each particular scientific tradition also has its particular characteristics.

First of all, since there is a raison d'être behind every tradition we need to find the causes or conditions that prepare the context for the rise of scientific traditions. This subject requires an analysis of the process that lead to such a tradition within a civilization. First of all, if there is no scientific activity in a society then there must be first in the minds of individuals a worldview which is suitable for cultivation of knowledge. This worldview is a characteristic of 
scientific traditions that carries with it a moral sensitivity. In fact this develops in a society initially which puts the society in a dynamic process of learning activities. It is possible to see this, for example in Islamic civilization which it had no sciences in its initial phase. It is important to realize that moral sensitivity, as the spirit of scientific traditions, towards the source of knowledge as conceived in that tradition which is imbedded in the worldview of the individuals of that society; towards existence in general, and then towards oneself, humanity and finally towards knowledge are preconditions for the rise of a scientific tradition. In the first place the learning activities lead to the accumulation of knowledge which first exemplifies a tradition of knowledge in that society. Without the existence of such a tradition no science will emerge in a society. Then the accumulated knowledge in the society is organized this way classified knowledge arises out of the chaotically accumulated knowledge. Then each class of knowledge is named as an area of study and defined as a "science". We thus take moral sensitivity together with its worldview as a fundamental characteristic of all scientific traditions.

Secondly, every scientific tradition has its own attitude towards knowledge in general and science in particular. This attitude may be identified as "scientific mentality". Since all mentalities are in one's worldview as conceptions, they form a unified understanding of science and knowledge. As such scientific mentality is grounded in the knowledge structure of a worldview.

Thirdly, a scientific tradition projects its own philosophical perception of existence and world conception reflected in the general worldview predominant in its own civilization. This way it will exhibit certain mental framework utilized by scientists active in that tradition. The most important of such a mental framework may be identified as the "General Scientific Conceptual Scheme"; but for short can be called the "Frame (of mind)" inculcated to the scientists during their training which is also reflected in their mentality as the characteristic of their scientific tradition. In the epistemological sense the worldview of the scientist represents his/her perspective and the general scientific conceptual scheme represents the frame of his mind which is formed by such concepts as knowledge, method, truth, theory and science. These two conceptual schemes, namely the perspective and the frame make up the core of a scientific tradition.

Moreover, since a scientific tradition assumes a social context it belongs to a civilization which has its own official language. It is usually this language that is utilized by scientists active in that civilization. Furthermore, because a scientific tradition has its own peculiar language it develops its own nomenclature. It may borrow technical terms from other traditions but it will gradually assimilate these terms and translate them into its own worldview as this was the case with the Greek scientific terminology when they were transferred into Arabic and most of them were gradually assimilated into the Islamic worldview.

Finally, a scientific tradition is continuous; as such it cannot be interrupted. For if there is an interruption it may not continue creatively as it is the case with Islamic scientific tradition today. Discontinuity will necessarily turn the members of that tradition to another civilization where they can find a continuous tradition. As we have indicated above this is a characteristic of all traditions whether scientific or otherwise. This is because traditions exhibit a historical process that cannot be disrupted. This characteristic tells us that a tradition cannot over cross to another civilization and sustain itself therein. We should not confuse mutual interaction with over crossing. Interaction and influence remains only local. Therefore, we cannot argue that Greek scientific tradition continued its existence in Islamic civilization because Islamic scientific tradition has its own characteristics which we do not find in Greek scientific tradition.

\section{Historical epistemology}

If we return to our application of historical epistemology to scientific traditions we find first epistemology of science and then since historical development takes place within the context of a social togetherness we find its sociology as well. In this respect epistemology of science in history has three broad perspectives for knowledge: epistemological; sociological and historical. The first perspective is epistemology of science proper. The second perspective is sociological because since epistemology of science in history is the continuity of epistemology of science proper in scientific activities that take place within a society, it necessarily assumes two types of social togetherness: one is the society at large and the second is the group of scholars who carry out that activity and as such they also form their own community within that society. The first togetherness gives us a sociological account of science and thus reveals a process in history which, as the third perspective, constitutes the epistemology of science in history. The latter togetherness provided continuity in history and this is what we identify as historical epistemology. The development of scientific knowledge in history is governed by our knowledge system which is manifested within a society. If we call the product which emerges as a result of this process we can see that it is multidimensional and it is because of this that makes it extremely difficult to come up with a uniform definition of science. If such a definition of science is possible then it must express all these dimensions in its formulation. As we have repeated over and over again we need epistemology of science as it works within history in order to explain the developments that take place within a scientific process. I would like to come up with a designation for this application of epistemology in history and call it "historical epistemology". What distinguishes this approach from earlier discussions of historical epistemology is that it does not diffuse epistemology throughout history but it rather takes epistemology as genetics of knowledge applied to groups of scholars across generations. 2 This way knowledge disseminates without being corrupted throughout history.

We may briefly compare this with Kuhn's approach to scientific revolutions. As this is well known if we briefly outline his approach we can see that Kuhn is basically interested in the historical process of scientific progress. As he points out his conclusions as generalizations are concerning "the sociology or social psychology of scientists"; however, he also states that "at least a few of my conclusion belong traditionally to logic or epistemology".9 This clearly shows that he is not interested in the epistemological foundation through which this process takes place. Kuhn is indeed efficient in explaining how passage takes place from normal science to progress through scientific revolution. But he is not investigating the epistemology which makes this passage possible because this is not his purpose. As he already indicated some of his generalizations belong to epistemology. We can see this, for example, in this question raised by Kuhn: "If normal science is so rigid and if scientific communities are so close-knit as the preceding discussion has implied, how can a change of paradigm ever affect only a small subgroup?"10 The statement that "scientific communities are so close-knit" indicates to the epistemology of that particular community which makes possible to transmit scientific knowledge from generation to generation because only human 
knowledge system as we briefly outlined above can provide such a close-knit characteristic to the group of scholars or scientists active in that community.

Now, if we summarize the historical process through which science progresses, according to Kuhn, we may argue that normal science "means research firmly based upon one or more past scientific achievements, achievements that some particular scientific community acknowledges for a time as supplying the foundation for its further practice."11 Kuhn calls these achievements "paradigms" which are "essential to scientific inquiry: no natural history can be interpreted in the absence of at least some implicit body of intertwined theoretical and methodological belief that permits selection, evaluation, and criticism."12 However, when scientists working in a particular paradigm gradually make new scientific discoveries certain parts of the paradigm becomes incoherent with these discoveries which lead to anomaly within the paradigm. Then the area of the anomaly is further explored which gradually leads to paradigm changes which result from the invention of new theories. This is because the existing theories fail to solve the problems defined by the new theory. It is this failure which is acknowledged as a crisis by the scientific community.

When scientists respond to such crisis they come up with new theories and they begin to search or develop alternative paradigms which may be compatible with new scientific discoveries. When a transition from former paradigm to its new alternative is complete, scientists within that scientific community begin to continue their scientific activities within that paradigm. The transition to a new paradigm is called "scientific revolution" by Kuhn.13 As it is clear Kuhn is not concerned with the underlying epistemology of this transition, which is what we identify here as "historical epistemology". $\mathrm{He}$ is primarily concerned with the nature and progress of scientific process in history. If we make a reference to Kant's critical exposition of human understanding we may say that historical epistemology is concerned with the transcendental background of this historical process, which makes the transition of all scientific knowledge possible throughout history. Another problem that Kuhn is facing is that he restricts his research to the history of science in Western civilization, whereas we consider scientific processes as independent as far as their respective civilizations are concerned.14 In fact if we are able to understand historical epistemology then we shall see that such processes may influence each other but cannot cross over their respective civilization, a fact which can be defended also on the basis of the epistemology of science.15-18

\section{Acknowledgements}

None.

\section{Conflict of interest}

The author declares that there is no conflict of interest.

\section{References}

1. Katherina Kinzel. Models of Historical Epistemology, Review of the book On Historicizing Epistemology: An Essay. Metascience. 2011;20(3):483486.

2. Randall Collins. The Sociology of Philosophies: A Global Theory of Intellectual Change. 4th ed. London: Harvard University Press; 2002. $1120 \mathrm{p}$.

3. Hans Jörg Rheinberger. On Historicizing Epistemology: An Essay. California: Stanford University Press; 2010. 128 P.

4. Kinzel. op. cit, 484.

5. Rhenberger. op. cit, 2-3.

6. Barry Stroud. Epistemology, the History of Epistemology, Historical Epistemology. Erkenntnis. 2011;75(3):495-503.

7. Philip Kitcher. Epistemology without History is Blind. Erkenntnis. 2011;75(3):505-524.

8. Mary Tiles. Is Historical Epistemology Part of the 'Modernist Settlement? Erkenntnis. 2011;75(3):525-543.

9. Thomas Sturm. Historical Epistemology or History of Epistemology? The Case of the Relation between Perception and Judgment. Erkenntnis. 2011;75(3):303-324.

10. Alparslan Açikgenç. The Impact of the Concept of 'Urf (Local Culture) in Islamic Legal Philosophy. Turkey: Religion and Law Review; 2013. 25 p.

11. Alparslan Acikgenc. Islamic Scientific Tradition in History. Kuala Lumpur: Penerbit IKIM; 2014. 562 p.

12. Thomas Kuhn. The Structure of Scientific Revolutions. 2nd ed. Chicago: The University of Chicago Press; 1970. 222 p.

13. Ibid, 49.

14. Ibid, 10

15. Ibid, 16-17.

16. Ibid, 90

17. Toby E. Huff. The Rise of Modern Science: Islam, China and the West. England: Cambridge University Press; 2003. 448 p.

18. Alparslan Acikgenc. Islamic Scientific Tradition in History. Malaysia: International Institute of Islamic Thought and Civilization; 2014. 562 p. 